\title{
LA CLÁUSULA PENAL EN EL CONTRATO DE LEASING Y SU NULIDAD POR FALTA DE CAUSA: UNA EVOLUCIÓN EN LA JURISPRUDENCIA
}

\author{
THE PENAL CLAUSE IN THE CONTRACT OF LEASING AND \\ HIS NULLITY FOR LACK OF CAUSE: AN EVOLUTION IN THE \\ JURISPRUDENCE
}

\section{COMENTARIO DE LA SENTENCIA DE LA CORTE SUPREMA, DE FECHA 2 \\ DE MARZO DE 2010 (ROL N 4626-2008).}

\begin{abstract}
Arturo Selman Nahum*
RESUMEN: El presente trabajo analiza la sentencia pronunciada por la Corte Suprema con fecha 2 de marzo de 2010, en recurso de casación en el fondo, la que viene a cambiar radicalmente el criterio asentado en los últimos años en la Corte de Apelaciones de Santiago, la que en múltiples ocasiones ha declarado la nulidad absoluta de una cláusula penal pactada en un contrato de leasing, por estimar que ella carece de causa.

Palabras clave: falta de causa, causa ilícita, cláusula penal, contrato de leasing.

ABSTRACT: The present work analyzes the sentence pronounced by the Supreme Court with date March 2, 2010, in resource of cassation in the background, which comes to change radically the criterion seated in the last years into the Court of Appeals of Santiago, which has repeatedly declared the absolute nullity of a penal clause agreed in a contract of leasing, considering that she has no cause.
\end{abstract}

Key words: lack of cause, illicit cause, penal clause, contract of leasing.

\section{INTRODUCCIÓN}

La causa, requisito de existencia y validez de todo acto jurídico ${ }^{1}$, presenta hasta el día de hoy un sinnúmero de problemáticas que enlodan su aplicación efectiva, lo que genera que los tribunales de justicia tiendan a no recurrir a ella para resolver un asunto sometido a su conocimiento. En efecto, pese a años de debate, aún se discute si lo que debe tener una causa es el acto o contrato, la obligación, o ambos ${ }^{2}$.

Ahora bien, la causa no es el único elemento complejo para estos efectos, también lo es el contrato de leasing, cuya figura, naturaleza jurídica y composición es de difícil de

\footnotetext{
* Licenciado en Ciencias Jurídicas y Sociales, Universidad Diego Portales; Abogado. Diplomado en Tributación, Universidad de Chile. Correo electrónico: arturo.selman@gmail.com.

${ }^{1}$ Tal afirmación dista de ser compartida en forma unánime por la doctrina, sobre todo aquella catalogada de anticausalista (Marcel Planiol entre sus principales exponentes).

${ }^{2}$ Tesis a la que adhiere Víctor Vial del Río. Véase: Vial (2006) p. 205.
} 
determinación, lo que unido a la siempre discutida cláusula penal, genera que el conflicto sometido a análisis no resulte de fácil solución.

Sobre la interrogante si la cláusula penal pactada en un contrato de leasing carece de causa o ella es ilícita, existen varios pronunciamientos a su respecto, razón por la cual se realizará un pequeño comentario a la jurisprudencia precedente, lo que resulta indispensable para comprender lo innovador de la sentencia objeto de estudio.

En efecto, la sentencia que se comentará en las páginas siguientes interesa no solo por la complejidad de los temas allí tratados, sino que también, plantea una solución original al problema que difiere a lo que la jurisprudencia ha fallado en los últimos años.

\section{HECHOS}

El Banco Crédito e Inversiones y la sociedad Comercial Traim Alimentos S.A., celebraron un contrato de arrendamiento con opción de compra respecto de un bien mueble, el que tendría un plazo inicial de 24 meses y cuya renta se pagaría mensualmente.

Los partes pactaron que el incumplimiento de cualquiera de las obligaciones del arrendatario, facultaría al arrendador -Banco Crédito e Inversiones- a poner término al contrato ipso-facto, exigir la restitución del bien arrendado, el pago de las rentas adeudadas, y por concepto de cláusula penal, el pago de una suma equivalente al $30 \%$ de las rentas pendientes a la época del incumplimiento.

La sociedad Comercial Traim Alimentos S.A. incumplió el contrato, cancelando solo hasta la cuota número 14, frente a lo cual el Banco Crédito e Inversiones demandó ante el $23^{\text {er }}$ Juzgado Civil de Santiago, solicitando la devolución del bien mueble, el pago de las rentas insolutas y la avaluación convencional y anticipada de los perjuicios.

El tribunal de primera instancia acogió la demanda en todas sus partes, condenando a la sociedad Comercial Traim Alimentos S.A. a restituir el bien mueble dentro de tercero día desde que la sentencia cause ejecutoria, y a pagar solidariamente a los demandados ${ }^{3}$ la suma de $\$ 2.720 .216$ por concepto de rentas impagas y $\$ 1.360 .305$ por concepto de cláusula penal.

Uno de los demandados, José Juan Llugany Rigo-Righi, dedujo recurso de apelación ante la Corte de Apelaciones de Santiago, la que en resolución de fecha 26 de mayo de $2008^{4}$, revocó la sentencia de alzada en la parte que condenaba al pago de $\$ 1.360 .305$ por avaluación anticipada de los perjuicios, declarando que por tal concepto no correspondía efectuar pago alguno, confirmado el fallo en lo restante.

Frente a la resolución de la Corte de Apelaciones, el demandante dedujo recurso de casación en el fondo argumentando la infracción de los artículos 1545, 1554, 1871, 1915 del Código Civil en relación con el artículo 19 del mismo cuerpo legal.

\footnotetext{
${ }^{3}$ Comercial Traim Alimentos S.A., Luis Arturo Basaure Valdivia y José Juan Llugany Rigo-Righi. Los últimos dos en calidad de codeudores solidarios.

${ }^{4}$ Banco Crédito e Inversiones con Comercial Traim Alimentos S.A. y otros (2008).
} 


\section{ANTECEDENTE PRELIMINAR: LA SENTENCIA DE LA CORTE DE APELACIONES DE SANTIAGO}

A efectos de comprender cabalmente el asunto objeto de análisis, se explicarán los principales argumentos que tuvo la Corte de Apelaciones de Santiago para revocar la sentencia de primera instancia y para declarar, en definitiva, la nulidad absoluta de la cláusula penal pactada en el contrato de leasing, fundado en una supuesta ilicitud o falta de causa.

En primer término, la Corte de Apelaciones sostuvo "que en la naturaleza del contrato de leasing es posible distinguir la unión de dos convenciones: un contrato de arrendamiento y un contrato de promesa de compraventa. Atendido lo anterior, en el precio que se paga existen dos items, el pago de la renta de arrendamiento y el pago de parte del precio del contrato prometido. En el presente caso se está demandando la entrega de la cosa arrendada, el pago total de las rentas de arrendamiento adeudadas en las que va implícito parte del precio de la cosa, y además a modo de cláusula penal el 30\% de lo adeudado".

Acto seguido, en su considerando tercero, señala: "que la causa es un requisito de existencia del acto jurídico $y$, además, la causa lícita es un requisito de validez del mismo, tal como expresamente lo indica el artículo 1.445 del Código Civil. Lo anterior es reafirmado por el artículo 1.467 inciso $1^{\circ}$, según el cual no puede haber obligación sin una causa real y lícita, aunque no es necesario expresarla, agregando el inciso $2^{\circ}$ que la causa es el motivo que induce al acto o contrato. Esto último ha llevado a la doctrina nacional a entender que la causa a que se refiere el artículo 1467 del Código Civil es un elemento de la obligación. No obstante ello, la doctrina moderna, Pablo Rodríguez Grez y Victor Vial del Río, ha objetado la tesis tradicional"6.

En su considerando quinto enfatiza: "que, en el caso en análisis, estamos en presencia de un contrato bilateral en el que es de la esencia que existan obligaciones correlativas, es decir, debe existir una correlación de obligaciones que juridicamente las justifica. De esta manera, si al demandado se le exige la entrega de la cosa mueble que fue objeto del contrato de leasing, la cláusula penal acordada en la convención carecerá de causa, ello porque dicha avaluación convencional está estructurada sobre la base de la renta de arrendamiento y del precio del contrato prometido. Como este último (la compraventa prometida) no llegará a verificarse no existe, en consecuencia, la obligación correlativa que constituye el propósito inmediato del promitente comprador, esto es, adquirir el dominio del inmueble. En otras palabras, en la forma que ha procedido el Tribunal a quo se ha obviado por completo la necesaria correlación y equilibrio de intereses que debe existir en un contrato bilateral, ya que la empresa demandante ha obtenido el pago de las rentas de arrendamiento y de parte del precio de la compraventa prometida durante el tiempo que duró la convención, ha demandado la entrega del bien mueble objeto del contrato $y$, además, reclama el cumplimiento de todas las

\footnotetext{
${ }^{5}$ Banco Crédito e Inversiones con Comercial Traim Alimentos S.A. y otros (2008). Considerando Segundo. Énfasis agregado.

${ }^{6}$ Banco Crédito e Inversiones con Comercial Traim Alimentos S.A. y otros (2008). Considerando Tercero.
} 
rentas futuras y de parte del precio de un contrato que no llegará a celebrarse. Desde luego que esta situación pugna con la licitud de la causa como elemento del acto jurídico".

Finalmente, en su considerando sexto, concluye: "Que esta Corte se encuentra facultada expresamente para declarar la nulidad absoluta de la cláusula penal estipulada en el contrato sub judice tal como expresamente lo reconoce el artículo 1.683 del Código Civil, toda vez que la nulidad absoluta puede y debe ser declarada por el juez, aun sin petición de parte, cuando aparece de manifiesto en el acto o contrato. En el caso que nos convoca basta con leer la forma en que está redactada la cláusula penal para concluir que, como se ha dicho en lo precedente, ella carece de causa, por cuanto en su cálculo se utiliza como factor a considerar el precio del contrato de compraventa prometido, el que no se celebrará. Por estas consideraciones y citas legales, y atendido también lo dispuesto en los artículos 144, 160 y 170 del Código de Procedimiento Civil, se revoca la sentencia apelada de dieciocho de octubre de dos mil seis, escrita a fs. 52 en cuanto en su decisión c) acoge la demandada disponiendo el pago de \$1.360.305 por concepto de cláusula penal de indemnización de perjuicios, y se declara que no se da lugar al pago de suma alguna por ese concepto, y se confirma en lo demás apelado dicho fallo".

Es importante destacar que la Corte incurre en un error conceptual al resolver el asunto, confundiendo los términos de ilicitud e inexistencia de la causa, los que evidentemente difieren entre sí. Así, la Corte en un primer momento señala: “(...) De esta manera, si al demandado se le exige la entrega de la cosa mueble que fue objeto del contrato de leasing, la cláusula penal acordada en la convención carecerá de causa", para luego afirmar: “(...) Desde luego que esta situación pugna con la licitud de la causa como elemento del acto jurídico”. Es del caso señalar que tal razonamiento carece de toda lógica, ya que un acto o contrato no puede carecer de causa y a la vez ser ilícita, puesto que para ser ilícita, la causa primero debe existir ${ }^{9}$.

En base a los argumentos esgrimidos por la Corte, se denota que su postura se inclina en la ilicitud de la causa, más que en su inexistencia. En esta misma línea Alejandra Aguad Deik, quien a propósito de una sentencia ${ }^{10}$ similar a la tratada aquí, señala: "En efecto, la tesis que sustenta, entre otros, el profesor Rodríguez en la obra antes citada es que la causa a que se refiere el art. 1467 del Código Civil es un elemento del contrato y no de la obligación. De ahi que la Corte haya preferido asilarse en esta doctrina para poder sentenciar la nulidad de la estipulación. Pero ocurre que la tesis del profesor Rodríguez, sobre la noción de causa, está intimamente ligada a la teoría bimembre de la nulidad que el mismo autor defiende en su obra Inexistencia y Nulidad en el Código Civil Chileno. En ella expresa que el rol de la causa consiste en entrelazar los elementos "voluntad" y "objeto" del negocio jurídico, pero no forma parte de la estructura de negocio (elemento de existencia), sino que es un requisito de validez. En este sentido, la ausencia de causa acarrearía la nulidad del negocio y no su inexistencia, pues concurriendo la voluntad y el objeto estaríamos en presencia de una "apariencia

\footnotetext{
7 Banco Crédito e Inversiones con Comercial Traim Alimentos S.A. y otros (2008). Considerando Quinto. Énfasis agregado.

${ }^{8}$ Banco Crédito e Inversiones con Comercial Traim Alimentos S.A. y otros (2008). Considerando Sexto.

${ }^{9}$ Imprecisión destacada anteriormente por la doctrina. Véase: Aguad (2005) p. 170 y De la Maza (2010) p. 183.

10 Santiago Leasing S.A. con Industrias de Remolques Indurem S.A. (2005).
} 
calificada por la ley"11. Entonces, y pese a la confusa terminología del tribunal de alzada, es dable concluir que la Corte se inclina por la ilicitud de la causa ${ }^{12}$.

Otro aspecto a considerar antes de continuar con el análisis de la sentencia de la Corte Suprema, es comprender la lógica utilizada por la Corte de Apelaciones para estimar que la cláusula penal carece de causa; que se resume básicamente en lo siguiente: al exigir el arrendador la restitución del bien, y al considerar las rentas pagadas como parte integrante del precio de un contrato prometido que no se celebrará, la obligación correlativa de la cláusula penal, no existiría, transformando esta última en incausada.

Finalmente, es importante destacar que este criterio ha sido utilizado en múltiples ocasiones por la Corte de Apelaciones de Santiago ${ }^{13}$, lo que hace más importante aún la sentencia que se analizará en las páginas siguientes. En efecto, interesa no solo por tratar temas de alta complejidad, sino que además impulsa una nueva línea jurisprudencial.

\section{COMENTARIO}

La Corte Suprema, en sentencia de fecha 2 de marzo de 2010, revocó la sentencia emitida por la Corte de Apelaciones de Santiago, disponiendo en su lugar que la cláusula penal resulta procedente en un contrato de leasing en que el arrendador solicita la restitución del bien, toda vez que la promesa de compraventa a la que alude la sentencia revocada no existe, resultando la compra del bien una opción para el arrendatario, más no una obligación. Así, el pago efectuado no forma parte del precio de un contrato que no se celebrará, por lo que la cláusula penal no carece de causa ni esta es ilícita como afirma el tribunal recurrido. Acto seguido, proporciona una visión innovadora sobre la causa, puesto que no solo se refiere a ella respecto del contrato principal, sino también del contrato accesorio (cláusula penal).

El párrafo anterior pretende resaltar las ideas principales de la postura adoptada por la Corte Suprema, permitiendo al lector conocer las ideas matrices del mismo, para así, pasar a estudiar uno a uno los argumentos vertidos por nuestro máximo tribunal, con el objetivo final de determinar si aquel razonamiento se adecua o no a la legislación vigente, y si significa un avance o retroceso respecto de la jurisprudencia que lo precede.

La Corte Suprema comienza por analizar la naturaleza jurídica del contrato de leasing. Así, en su considerando cuarto señala: "Que para dilucidar la exacta naturaleza del contrato entre las partes, es relevante tener en consideración la estipulación $7 a$, párrafo $2^{\circ}$ del instrumento que lo contiene, corriente a fojas uno y siguientes. Conforme a ella, "Al término del arrendamiento la arrendataria podrá optar por alguna de las siguientes alternativas: a) Devolver el bien arrendado a la arrendadora; b) Celebrar un nuevo contrato de arrendamiento, o bien, c) Comprar el bien arrendado".

\footnotetext{
11 Aguad (2005) p. 170.

12 Sin perjuicio de lo anterior, en el desarrollo de este trabajo se hará referencia a ambos conceptos, ya que la Corte de Apelaciones los utiliza indistintamente.

${ }^{13}$ Véase por ejemplo: Santander Factoring S.A. con Genova Nualart, Luis (2006); Hns. Banco S.A. con Marshall Villanelo, Manuel (2008); y Santiago Leasing S.A. con Rimpex Chile S.A. (2008).
} 
De su tenor se puede inferir que la compra es solo una de las tres opciones concedidas al arrendatario, al término del contrato, conviniéndose complementariamente que este derecho para cuya materialización el Banco arrendador formula una oferta irrevocable, fijando el precio de la compraventa en una suma determinada, en la misma cláusula 7 a caducará si la arrendataria incurre en cualquier incumplimiento de las obligaciones que le corresponden.

Además, se convino en que la tal opción debia hacerse efectiva en el plazo de los últimos 30 dias de vigencia del contrato, mediante comunicación escrita al banco arrendador y que, omitida la comunicación, "se entenderá que (el arrendatario) ha optado por la alternativa indicada en la letra a)".

Es evidente, entonces, que la convención en análisis representa un contrato de arrendamiento con opción de compra de un bien mueble y no un arrendamiento y un contrato de promesa de compraventa, como asevera el motivo $2^{\circ}$ del fallo recurrido, desde que esta segunda posibilidad expresa solo una de las tres opciones abiertas al arrendatario en la referida cláusula $7 a$, la que, adicionalmente, caducó, desde que este último incurrió en mora en el pago de las rentas que debió solventar, hecho que no se discute"14.

Resulta evidente que tal razonamiento difiere al criterio asentado en la Corte de Apelaciones de Santiago, puesto que considera a este contrato atípico, como un arriendo con diversas opciones para el arrendatario, eliminando toda posibilidad de entender que en aquel se configura -implícitamente- una promesa de compraventa. En efecto, por esta sola circunstancia, la Corte estima que el tribunal recurrido infringió los artículos 1554 y 1555 del Código Civil, ambos relacionados con el artículo 19 del referido cuerpo legal.

Ahora, si damos por correcto que el leasing es un arriendo con opción de compra, surge la interrogante si aquel es la unión de dos convenciones, o por el contrario, es un negocio jurídico particular. A este respecto, Álvaro Puelma Accorsi se inclina por la última opción ${ }^{15}$, argumentado que para que el leasing se entienda como una unión de convenciones, ellas deben mantener sus características propias, lo que no ocurriría, en su opinión, con el contrato de opción, perdiendo su unilateralidad. Se difiere de esta postura, ya que el contrato de opción puede ser bilateral, sobre todo cuando estamos frente a un "contrato de opción con precio o prima"16, lo que en caso alguno significa que lo pagado forme parte del precio de compraventa, mientras no se haga uso de la opción de compra.

Pese a esta dificultad ${ }^{17}$, entender el leasing de una u otra forma no resulta determinante para la cuestión aquí debatida, ya que ninguna de estas opiniones entiende incorporada en el una promesa de compraventa.

De esta forma queda en evidencia que la naturaleza jurídica del leasing no se encuentra exenta de dificultades, así por ejemplo, Rafael Gómez Balmaceda “(...)advierte que se le anexan y yuxtaponen al mismo contrato distintos negocios jurídicos, como son entre otros, el mandato, la compraventa y la opción de compra que, intimamente concatenados, alteran los efectos naturales y corrientes que emanan del contrato de arrendamiento, con lo que se le infun-

\footnotetext{
${ }^{14}$ Banco Crédito e Inversiones con Comercial Traim Alimentos S.A. y otros (2010). Considerando Cuarto. Énfasis agregado.

15 Puelma (2002) pp. 108-109.

${ }^{16}$ Fueyo (1964) p. 35.

${ }^{17} \mathrm{La}$ que esta lejos de ser resuelta.
} 
de al fenómeno del leasing la particularidad de tener una fisonomía propia, más bien de indole sui generis o si se quiere, atipica"18. Pese a su complejidad, se concuerda con la calificación jurídica del leasing efectuada por la Corte Suprema, el que, considerado como un conjunto de convenciones, incluye un contrato de opción y no una promesa de compraventa.

Expuesto lo anterior, se denota que la principal diferencia respecto del criterio adoptado por la Corte de Apelaciones de Santiago, dice relación con entender que el leasing contendría una opción de compra en vez de una promesa de compraventa. Así, la opción de compra es facultativa para el arrendatario, diferenciándose de la promesa de compraventa, contrato que en su esencia es de aquellos denominados preparatorios de celebración.

En este mismo sentido Fernando Fueyo Laneri, quien a propósito del contrato de opción señala: “(...) como contrato, difiere a la vez de otras figuras preparatorias, como ser, el contrato de promesa de celebrar contrato, sea unilateral o bilateral (...)"19.

"En comparación con el otro contrato de preparación que se ha estudiado anteriormente (Art. 1554 del Código Civil, en nuestro ordenamiento), aqui funciona una modalidad que, justamente, lo tipifica. Es el evento de la decisión del que goza del derecho de opción, que, concretamente, es la decisión de aceptar. No es, por tanto, preparatorio de la celebración de un contrato futuro que obligadamente deberán celebrar los dos concertantes de hoy, como en la promesa bilateral; ni de la celebración a instancia del que hoy no queda obligado, como en la promesa unilateral"20.

Otra cuestión de difícil determinación, se refiere a si el contrato de leasing contiene un contrato de opción -como afirma la Corte Suprema- o un contrato de promesa unilateral $^{21}$. Resolver esta interrogante no es de fácil solución, ya que ambos contratos presentan variadas similitudes. A este respecto, Antonio Ortúzar Solar señala: "el contrato de opción, al nacer normalmente, es vinculante para el otorgante por adelantar y traspasar su voluntad al destinatario de la oferta. El contrato de promesa requiere siempre que la voluntad del contrato a celebrar se cristalice con motivo de la celebración del contrato prometido"22.

En efecto, la principal diferencia entre uno y otro, radica que en el contrato de opción bastará la aceptación del optante para que se perfeccione el contrato respecto del cual el obligado efectuó la oferta irrevocable, sin la necesidad de que este último manifieste de nuevo su voluntad ${ }^{23}$.

Cabe destacar que la redacción del contrato jugará un papel importante a la hora de determinar su naturaleza jurídica. En el caso que nos atañe, la Corte Suprema, explicó los términos en que se redactó el contrato de leasing suscrito por los contratantes y que es objeto de análisis, disipando toda duda -en opinión del autor- acerca de su contenido y naturaleza jurídica.

\footnotetext{
18 Gómez (2006) p. 7.

19 Fueyo (1964) p. 67.

${ }^{20}$ Fueyo (1964) p. 33. Énfasis agregado.

${ }^{21}$ Cabe señalar que la promesa unilateral de celebrar un contrato bilateral es un tema discutido, cuya validez tiene múltiples detractores.

22 Ortúzar (1995) p. 54. Autor de la obra más completa que existe en Chile sobre el contrato de leasing.

23 Ortúzar (1995) p. 53.
} 
Entonces, se puede afirmar que el contrato de leasing redactado en los términos indicados por la Corte Suprema, es un contrato de arriendo que incluye un contrato de opción a favor del arrendatario, quien podrá decidir a su arbitrio ${ }^{24}$, utilizar la opción de compra, devolver el bien o renovar el contrato.

Dilucidada la naturaleza jurídica del contrato de leasing, cuestión de esencial importancia según se expondrá más adelante, corresponde analizar los argumentos de la Corte, en orden a sostener la existencia y licitud de la causa.

A este respecto, la Corte Suprema afirma que: “(...) mal podría calificarse como carente de causa dicha avaluación anticipada, si su fundamento es precisamente la convención pactada, en ejercicio del principio de autonomía de la voluntad, recogido tan categóricamente en el mentado artículo 1.545.

Para arribar a ese enfoque, discurre el pronunciamiento objetado a partir de la consideración que la avaluación convencional de los perjuicios se estructuró sobre la base de "la renta de arrendamiento y del precio del contrato prometido", en circunstancias que, como se explicó, la estipulación pactada consistió en un arrendamiento de cosa mueble con opción de compra, por lo cual el mecanismo de cálculo utilizado se centró en el valor de las rentas no vencidas a la época de la primera cuota impaga, como subraya el recurso. Este fundamento de cómputo es perfectamente ajustado a la ley del contrato y a los términos del artículo 1.553, ya citado.

En consecuencia, constituido en mora el arrendatario con motivo del no pago de la renta de arrendamiento correspondiente a diciembre de 2005, el arrendador ha podido reclamar legitimamente el cumplimiento de la indemnización convenida en la cláusula $12^{a}$ del contrato de fojas 1 , por aplicación de los artículos 1.553 y 1.557, por ajustarse esta inferencia a la clara intención de los contratantes, al sentido en que la estipulación penal puede producir algún efecto y a la interpretación del articulado de la convención entre las partes unas por otras, dándose a cada una el sentido que mejor convenga al contrato en su totalidad, en armonía con la interpretación correcta que cabe atribuir a los articulos $1.560,1.562$ y 1.564 del Código Civil, vulnerados en la forma en que fueron aplicados por los jueces del fondo.

Asumido que es esta la inteligencia que debe asignarse a las citadas normas, salta a la vista que la sentencia impugnada no carece de causa real y lícita, entendida esta como el motivo que induce al acto o contrato, puesto que ese motivo no es otro que el incumplimiento del arrendatario en el pago de las rentas, que obliga al moroso a pagar los perjuicios avaluados en una cláusula penal libremente convenida. Luego, cabe tener por establecido que el fallo recurrido ha dado falsa aplicación al artículo 1.467 del Código Civil, en la medida que la estipulación penal pactada no carece de causa ni esta es ilícita, como se sostiene"25.

Antes de comenzar el análisis de fondo y tal como lo expone Iñigo de la Maza Gazmurio $^{26}$, es menester aclarar que la sentencia incurre en un error de redacción al señalar: “(...) salta a la vista que la sentencia impugnada no carece de causa real y lícita (...)", puesto

\footnotetext{
${ }^{24}$ Siempre que se hayan pagado las rentas de arrendamiento, las que canceladas en su totalidad, permiten al arrendatario optar a lo que mejor le parezca.

${ }^{25}$ Banco Crédito e Inversiones con Comercial Traim Alimentos S.A. y otros (2008). Considerando Sexto. Énfasis agregado.

${ }^{26}$ De la Maza (2010) p. 184.
} 
que el razonamiento que expone la Corte se refiere a la cláusula penal y no a la sentencia impugnada.

Aclarado lo anterior, para nuestro máximo tribunal la sentencia recurrida presenta ciertos errores insalvables. El primero de ellos es afirmar que la cláusula penal carece de causa, cuando ella es la convención pactada por los contratantes. En otras palabras, para la Corte resulta evidente que la cláusula penal tiene causa, cual es, el contrato de leasing pactado libremente por las partes en virtud del principio de autonomía de la voluntad.

Pese a lo anterior y en un extraño giro, complementa además que la causa de la cláusula penal, como acto accesorio al contrato, no puede ser otra que el incumplimiento del arrendatario en el pago de las rentas ${ }^{27}$.

Es decir, la obligación del arrendatario de indemnizar los perjuicios avaluados anticipadamente, tiene como causa directa el incumplimiento de sus propias obligaciones.

Entonces, la interrogante que se plantea es si debe considerar la causa del contrato accesorio o la del contrato principal. En efecto, la cláusula penal es una estipulación accesoria al contrato de leasing, cuya causa difiere del incumplimiento concebido como tal. Entonces el inclinarse por una u otra postura, parece, en principio, de suma relevancia.

Así, estimar que la causa a considerar es la del contrato accesorio, significa, en definitiva, eliminar el problema de la base de cálculo de la cláusula penal expuesto por la Corte de Apelaciones, ya que aunque se estime que lo pagado forma parte del precio de un contrato que no se celebrará, la causa directa sería el incumplimiento del deudor. Ahora bien, si se utiliza la causa del contrato principal, importará de sobre manera la calificación jurídica del leasing, y si aquel incorpora o no, un contrato de promesa de compraventa.

Frente a esta interrogante y compartiendo la opinión de Iñigo de la Maza Gazmu$\mathrm{ri}^{28}$, se estima que la cláusula penal tiene como causa directa el contrato principal del que forma parte como estipulación accesoria. En apoyo a lo anterior, Avelino León Hurtado concluyó: "Si el propio deudor constituye una prenda, hipoteca o anticresis, la causa de la obligación de garantía, es la misma de la obligación principal, si se constituye conjuntamente con ella"

Es dable sostener entonces, que la cláusula penal tiene como causa la del contracto de leasing, que de conformidad al asunto controvertido, para el arrendador será el pago que reciba, y para el arrendatario, el uso y goce del bien objeto del contrato, con la opción, entre otras, de comprarlo ${ }^{29}$.

Para el caso de análisis, inclinarse por una u otra postura, sorprendentemente, no resulta determinante a la hora de justificar la existencia o licitud de la causa. En efecto, si consideramos como causa la del contrato accesorio, ella sería el incumplimiento, y si consideramos como causa la del contrato principal, ella sería el propio contrato de leasing ${ }^{30}$. Es decir en ambos casos, habría una causa real y lícita. Lo anterior se debe a que la Corte Suprema niega toda posibilidad de que el leasing incorpore una promesa de compraventa, impidiendo utilizar así, el argumento de la Corte de Apelaciones de Santiago. Entonces,

\footnotetext{
${ }^{27}$ Esta afirmación -aparentemente correcta- no deja de ser discutible.

28 De la Maza (2010) p. 184.

${ }^{29}$ Entendida como causa final.

${ }^{30}$ Entendido como un arriendo con opción de compra.
} 
inclinarse por una u otra postura no altera la existencia y licitud de la causa, aunque dependiendo de la opción que se adopte ella variará.

Recordemos que la primera parte de la sentencia vino a resolver la naturaleza jurídica del contrato de leasing, concluyendo que aquel no implica de forma alguna una promesa de compraventa.

Refuerza lo recién expuesto el considerando séptimo, el que categóricamente afirma: "Que, finalmente, en el último capitulo de casación se objeta la aplicación que hacen los jueces de segunda instancia de la facultad reconocida en el artículo 1.683 del Código Civil en orden a declarar la nulidad absoluta de la cláusula penal, a la que se califica como carente de causa, "por cuanto en su cálculo se utiliza como factor a considerar el precio del contrato de compraventa prometido, el que no se celebrará" (consid. $6^{\circ}$ ).

Al respecto, cabe manifestar que, definida la naturaleza jurídica del contrato entre las partes, que es de arrendamiento y opción de compra y no de promesa de celebrar contrato, ninguna relación existe entre el precio de una compraventa que no podrá realizarse, con ocasión de la mora del arrendatario, y la base de cálculo de la aludida cláusula penal"31.

En otras palabras, aunque se discuta si se debe utilizar la causa del contrato principal o la del contrato accesorio, de todas maneras se niega la posibilidad que la cláusula penal carezca de causa por haberse utilizado como base de cálculo el precio de una compraventa que, en definitiva, no se celebrará, toda vez que el contrato de leasing no incorpora promesa alguna de compraventa, por lo que la base de cálculo de la cláusula penal incluye únicamente las rentas de arrendamiento.

En este sentido se desmorona el criterio de la Corte de Apelaciones de Santiago, cuyo fundamento principal en aras de argumentar la inexistencia o ilicitud de la causa ${ }^{32}$, era sostener que la base de cálculo incluía parte del precio de un contrato de compraventa prometido que no se iba a celebrar, resultando la obligación correlativa incausada.

De lo razonado en estas páginas, se concluye que la naturaleza jurídica del contrato de leasing resulta fundamental para resolver la procedencia o improcedencia de la cláusula penal pactada en el.

Así, entender el contrato de leasing como un arriendo con opción de compra, implica que el arrendatario podrá optar, indistintamente, por la compra del bien, la renovación del contrato o la restitución del bien. Es decir, mal puede entenderse que la renta pagada forme parte del precio de la compraventa, mientras el arrendatario no opte por la compra del bien. Por lo tanto, mientras el arrendatario no decida utilizar la opción de compra, lo pagado simplemente corresponderá a la renta de arrendamiento.

En consecuencia, en el evento de demandar la cláusula penal por incumplimiento del arrendatario, la causa no solo existe, sino que es real y lícita, resultando en definitiva la convención pactada por los contratantes.

\footnotetext{
31 Banco Crédito e Inversiones con Comercial Traim Alimentos S.A. y otros (2008). Considerando Séptimo. Énfasis agregado.

${ }^{32}$ Esta dualidad se debe -como se dijo- a que la Corte de Apelaciones utiliza indistintamente los conceptos de ilicitud e inexistencia.
} 
Ahora bien, lo razonado precedentemente podría presentar ciertos inconvenientes, por ejemplo el arrendatario podría demostrar en el juicio que su intención era comprar el bien, argumentando que lo pagado no solo correspondía a una renta de arrendamiento, sino que también a parte del precio de la compraventa, en cuyo caso el tribunal podría hacer suyo el criterio de la Corte de Apelaciones de Santiago.

Sin perjuicio de lo anterior, se estima incorrecta tal apreciación, ya que significaría estar a merced del contratante incumplidor, quien lógicamente podría utilizar esto a su favor. En consecuencia, lo pagado solo formará parte del precio de la compraventa una vez que el arrendatario pague la totalidad de las rentas y haga uso de la opción de compra en el tiempo y forma pactado.

\section{CONCLUSIONES}

La sentencia de la Corte Suprema, en primer lugar, clarifica la naturaleza jurídica del contrato de leasing, señalando que aquel incorpora un contrato de arriendo con opción de compra, derrumbando la tesis sostenida por la Corte de Apelaciones de Santiago, que atribuía en el una convención compuesta por un arriendo y una promesa de compraventa.

Se estableció que si bien, tanto el contrato de opción como el de promesa de compraventa son contratos de preparación, ellos presentan diferencias claras, lo que se traduce al caso en particular, que el pago mensual efectuado por el arrendatario no corresponde a parte del precio de la compraventa, mientras no se opte, en tiempo y forma, por la opción de compra.

Así, no es dable sostener que la cláusula penal carece de causa o ella es ilícita amparándose en que su base de cálculo comprende parte del precio de un contrato que no se celebrará, ello porque el leasing no incorpora una promesa de compraventa, sino solo una opción de compra.

En segundo lugar, la Corte Suprema justifica la existencia y licitud de la causa, tanto del contrato principal como de la estipulación accesoria. A este respecto, se explicó que no parece correcto tipificar al incumplimiento como causa de la avaluación anticipada de los perjuicios, ello porque al tratarse de una estipulación accesoria, comparte la causa del contrato principal.

Pese a esta imprecisión, se señaló que no resulta un aspecto fundamental a la hora determinar la existencia y licitud de la causa. En efecto, independiente de la postura que se adopte, mientras se califique el contrato de leasing como un arriendo con opción de compra, se impide utilizar el argumento de que la obligación sería incausada, por estimar que la base de cálculo de la cláusula penal incluiría parte del precio de un contrato que no se va a celebrar.

En definitiva, la sentencia comentada no solo justifica la existencia y licitud de la causa, sino que además determina la naturaleza jurídica del contrato de leasing, estableciendo así un doble argumento para rechazar la tesis que por años ha utilizado la Corte de Apelaciones de Santiago. 


\section{BIBLIOGRAFÍA CITADA}

Aguad Deik, Alejandra (2005): “Obligaciones y Responsabilidad Civil”, Revista Chilena de Derecho Privado, No 5: pp. 167-174.

Fueyo Laneri, Fernando (1964): Derecho Civil Tomo V, Los contratos en particular, y demás fuentes de las obligaciones, Vol. II (Santiago, Imprenta y Lito. Universo S.A., 2a edición) 287 pp.

Gómez Balmaceda, Rafael (1996): Leasing, Gaceta Jurídica, Nº 192: pp. 7-13.

León Hurtado, Avelino (1961): La Causa (Santiago, Editorial Jurídica de Chile) 92 pp.

Ortúzar Solar, Antonio (1995): El Contrato de Leasing (Santiago, Editorial Jurídica de Chile, $1^{\text {a }}$ edición) 219 pp.

Puelma Accorsi, Álvaro (2002): Contratación Comercial Moderna (Santiago, Editorial Jurídica de Chile, $1^{\text {a }}$ edición) 213 pp.

Vial del Río, Víctor (2006): Teoría General del Acto Jurídico (Santiago, Editorial Jurídica de Chile, 5a edición) 407 pp.

\section{NORMAS CITADAS}

Código Civil de la República de Chile (2008) (Santiago, Editorial Jurídica de Chile, $18^{\text {a }}$ edición): artículos 19, 1445, 1467, 1545, 1553, 1554, 1555, 1557, 1560, 1562, 1564, 1683,1871 y 1915.

Código de Procedimiento Civil de la República de Chile (2008) (Santiago, Editorial Jurídica de Chile, 19a edición): artículos 144, 160 y 170.

\section{JURISPRUDENCIA CITADA}

Banco Crédito e Inversiones con Comercial Traim Alimentos S.A. y otros (2008): Corte de Apelaciones de Santiago, 26 de mayo de 2008 (término de contrato de arriendo), Rol $\mathrm{N}^{\circ}:$ 10671-2006, disponible en www.poderjudicial.cl.

Banco Crédito e Inversiones con Comercial Traim Alimentos S.A. y otros (2010): Corte Suprema, 2 de marzo de 2010 (término de contrato de arriendo), Rol N: 4626-2008, disponible en www.microjuris.cl, $\mathrm{N}^{\circ}$ identificador de documento: MJJ23483.

Hns. Banco S.A. con Marshall Villanelo, Manuel (2008): Corte de Apelaciones de Santiago, 2 de julio de 2008 (término de contrato de arriendo), Rol N: 3381-2007, Gaceta Jurídica, $\mathrm{N}^{\circ} 337$, p. 129.

Santander Factoring S.A. con Genova Nualart, Luis (2006): Corte de Apelaciones de Santiago, 29 de diciembre de 2006 (término de contrato de arriendo), Rol Nº 60372001, Gaceta Jurídica, No 318, p. 195.

Santiago Leasing S.A. con Industrias de Remolques Indurem S.A. (2005): Corte de Apelaciones de Santiago, 2 de mayo de 2005 (término de contrato de arriendo), Rol $\mathrm{N}^{\circ}:$ 1045-2000, Gaceta Jurídica, $\mathrm{N}^{\circ} 299$, p. 175.

Santiago Leasing S.A. con Rimpex Chile S.A. (2008): Corte de Apelaciones de Santiago, 29 de abril de 2008 (término de contrato de arriendo), Rol No: 4270-2004, Gaceta Juridica, $\mathrm{N}^{\circ} 334$, p. 144. 